\title{
Developing a supervisor identity through experiential learning: Narratives of three novice academics working in a South African University
}

\section{Sibonelo Blose}

School of Education, University of KwaZulu-Natal, Durban, South Africa Bloses@ukzn.ac.za https://orcid.org/0000-0002-7328-6383

\section{Vusi Msiza}

School of Education, University of KwaZulu-Natal, Durban, South Africa Msizav@ukzn.ac.za https://orcid.org/0000-0003-1178-136X

\section{Freedom Chiororo}

School of Education, University of KwaZulu-Natal, Durban, South Africa freedomchiororo@gmail.com https://orcid.org/0000-0003-2756-8336

(Received: 10 July 2020; accepted: 17 November 2020)

\section{Abstract}

One of the critical tasks of academics in any research-intensive university is the supervision of postgraduate students. Given the central role of this activity, how novice academics learn to supervise is significant. In this paper, we present our narratives as novice academics, and we focus on our learning of the supervision role. We drew from experiential learning and role identity theories to frame our understanding of this process. Using a narrative inquiry methodology, we shared and examined our narratives of lived experiences as novice supervisors. Upon examining our narratives, we identified four sources of learning that were significant in developing our supervisor identity: our current or previous supervisors; senior colleagues; meaningful corridor talks; and the practice of reflexivity. We recommend that institutions of higher learning pay added attention to the development of novice supervisors. Although structured programmes are significant, other learning avenues need to be explored to assist novice supervisors to develop a supervisor identity.

Keywords: supervision, novice supervisor, experiential learning, narrative inquiry, role identity 


\section{Introduction}

The supervision of research is generally perceived to be a process of providing guidance and support to students (McCallin \& Nayar, 2012; Sambrook et al., 2008; Yousefi et al., 2015), and it is a key responsibility of an academic in any research-based university. The lastmentioned claim that the supervision process involves many functions, including creating professional relationships, encouraging students to study, providing guidance on their research projects, and assisting them with their personal and general problems. Although these functions do not occur in a linear process, they are significant for successful supervision (Sambrook et al., 2008; Yousefi et al., 2015). According to Abiddin et al. (2011), supervision is a complex exercise because it involves two or more parties with converging and diverging interests.

When new academics are appointed in a university, there is a common assumption that they know what is expected of them, and as novice academics, we experienced this. Manathunga and Goozée (2007) have confirmed this presumption and explained that supervisors are expected to become effective automatically once they had experienced the supervision process themselves. Because of this, novice supervisors often repeat the supervision approaches that they experienced while they were students (Manathunga \& Goozée, 2007). Recently there has been an increased governmental interest in higher degree studies (Manathunga \& Goozée, 2007) and a great emphasis on fast-tracking research and throughput at the postgraduate level (Khunou et al., 2019). This is evident in the National Planning Commission's (2012) target to increase $\mathrm{PhD}$ output from the current 1500 per annum to 5000 per annum by 2030. For Maistry (2017) this is an exaggerated and unrealistic target that indicates the influence of a strong neoliberal knowledge-economy agenda for higher education in South Africa. On account of this neoliberal trajectory, supervisors experience the pressure to meet governmental demands, but this often works against producing high-quality, original research output (Lee, 2007). Despite this neoliberal knowledge-economy with its pressures, our focus is on supervision for knowledge production.

The drive for institutions to produce more research makes the supervision of research more critical. However, the academic staff complement in many universities is not made up solely of senior and experienced academics given the considerable number of novice academics working in them. For Maistry,

[g]iven that under 35 percent of all academics in South Africa hold a $\mathrm{PhD}$ qualification and [that] the country is characterised by substantial numbers of novice and inexperienced supervisors, the liminal becomes a crucial nexus that will influence the future strength of the South African higher education sector. (2017, p. 132)

Additionally, the research output in South Africa is linked to a financial benefit for institutions so the research-intensive institutions are most likely to become financially stronger and to attract good researchers, while universities with low research output are not attractive to experienced researchers. 
When we conceptualised this paper, each of us had had fewer than two years of supervision experience, and we were working on our doctoral studies. We were already each supervising between 10 and 15 Honours students and we were each co-supervising between 1 and 2 Masters students. Although the employing university offered a structured course on supervision, which two of us attended, we found the course inadequate. It could not cover much information since it ran over only three days and, since delegates were from different disciplines, it provided only an overview of supervision. Given the inadequacy of the course, we then explored different ways of learning more about the supervision role and thus gained confidence in how to carry it out. McCallin and Nayar (2012) described supervision as a professional activity that may be learned through a combination of improved theoretical understanding and active participation in the process itself. In this paper, we focus on our learning, which occurred while we were actively participating in the supervision process. Without suggesting that the structured supervision training programme was insignificant, we reflect on our experiences of supervising postgraduate students to uncover what contributed to our learning of the role. The key puzzle (known as a key question in other methodologies) was: What sources of learning are contributing to our supervisor identity development as novice academics in a higher education institution?

\section{Preparing novice supervisors for the supervision role}

The supervision of postgraduate students is regarded as a form of mentoring that enables students to master, gradually, appropriate disciplinary research knowledge (Manathunga \& Goozée, 2007). This process is intellectually and emotionally demanding for both supervisors and students (McCallin \& Nayar, 2012) so the preparation of those who will become or are becoming supervisors needs to be considered carefully by different disciplines in universities if they are to ensure quality learning and research output. The common requirement from a supervisor in most contexts is the possession of a degree that is, at least, equivalent to, or higher than that towards which the candidate is aiming. In the United Kingdom and Australia, for example, supervisors are expected to have served previously as associate or cosupervisors and to have supervised to completion (Abdullah \& Evans, 2012). Through cosupervision, novice supervisors have the opportunity to work closely with veteran supervisors to help them learn and gain the necessary experience (Lee \& Murray, 2015).

Apart from co-supervision, novice supervisors can also be prepared for their role through training or through completing a course (Abdullah \& Evans, 2012; Frick \& Glosoff, 2014; McCallin \& Nayar, 2012). Some South African universities offer accredited research supervision courses to their novice academics and to those in fellow universities. (One such programme, "Strengthening Postgraduate Supervision" is on offer through the Centre for Higher Education, Teaching and Research (CHERTL) at Rhodes University). This programme was developed by research supervisors from South African tertiary institutions (including Rhodes University, University of Fort Hare, University of Cape Town, Stellenbosch University, and the University of Venda) in collaboration with a team of experienced research supervisors from the Netherlands Universities Foundation for International Cooperation (NUFFIC), as Maistry (2017) has noted. McCallin and Nayar 
(2012) have argued that the formal training of supervisors is significant since it may prevent or at least reduce the number of trial-and-error attempts that novice supervisors tend to make.

Even where the training of supervisors is perceived to be essential and is held in high regard, novice supervisors in some contexts still feel incompetent at supervising students (Frick \& Glosoff, 2014). Manathunga (2005) has argued that the focus of induction programmes should be on pedagogy in supervision instead of on administrative approaches. According to Leshem et al. (2013) and Chikte and Chabillal (2016), there should be formal, consistent, and ongoing capacity building workshops on supervision that are necessarily carried out in research-intensive universities. The team or group supervision practice that has recently become one of the ways in which institutions encourage collaborative learning and motivate supervisors with different credentials and experience to engage in critical conversations (Khene, 2014; Manathunga, 2005) would meet this need.

There are many sources upon which novice supervisors draw in their learning how to supervise. These include their previous work experience, attendance at conferences, studying literature on supervision, and their observations of current and previous supervisors (Frick \& Glosoff, 2014). The last-mentioned resource, in particular, seems to be the most influential factor in the development of the supervisory practices of developing novice supervisors. According to Frick and Glosoff (2014), one of the principal ways in which novice supervisors gain self-efficacy is through interacting with, observing, and soliciting support from current or previous supervisors.

\section{Theoretical framework}

This study is underpinned by two theories: Kolb's experiential learning theory (1984); and Stryker's (1968) role identity theory.

We adopted the experiential learning theory so as to understand our learning process as novice supervisors. According to Kolb (1984), learning requires individuals to recall and reflect on their past experiences for new knowledge to be acquired. He stated that "the simple perception of the experience is not sufficient for learning; something must be done with it" (p. 42). Essentially, new knowledge is developed by transforming and modifying past experiences. This is referred to as grasping and transforming the experiences (Kolb, 1984; Kolb et al., 2001). From this perspective, learning is conceptualised as a process of engaging with experience, which then results in re-learning (Kolb \& Kolb, 2005).

Kolb (1984) put forward a four-stage cycle that displays a learning process; it includes the concrete experience, reflective observation, abstract conceptualisation, and active experimentation. First, concrete experiences, dominated by the senses, are regarded as a starting point for learning (see, too, Roberts, 2006). Second, reflective observation involves breaking down knowledge into pieces before it is internalised (Roberts, 2006). Third, abstract conceptualisation pertains to the formation of rules, generalisation, and concepts (Kolb, 1984; Roberts, 2006). Finally, active experimentation is about putting into practice the new learnings. 
The role identity theory, engineered by Stryker (1968) to help understand people's selfconstruction in social roles, describes society as a complex, differentiated, but organized phenomenon, and, since people operate in different societies, they are perceived as reflections of the societies within which they dwell. From Stryker's perspective, individuals have distinct components of self for each of the role positions they occupy in society; he refers to role identities that include, among others, familial roles (daughter, son, mother, husband and so on), occupational roles (doctor, teacher, salesman, engineer, etc,), and political roles (political party delegate, party leader, and such like)

Adding to Stryker's conception, McCall and Simmons (1978) described a role identity as a character and a role that an individual devises for him/herself as an occupant of a particular social position; it is an imaginative view of oneself as an occupant of a particular position. Similarly, Hogg et al. (1995, p. 256) delineated the role identity as "self-conceptions, selfreferent cognitions, or self-definitions that people apply to themselves as a consequence of the structural role position they occupy and through a process of labelling or self-definition as a member of a particular social category."

In this paper, we blend the theories of experiential learning and role identity to try to understand our learning and self-cognition as novice supervisors that occurred largely on the job, and we applied the four-stage cycle of the experiential learning theory to track our learning process. Additionally, we perceived being a supervisor as a social role, and, as novices in this role, all our learning contributed to our self-cognition. In this way, role identity theory helped us understand a plethora of factors that contribute to our selfconceptions, self-referent cognitions, and self-definitions as novice occupants of the supervisor role. Therefore, these two theories served collectively as our cognitive tool with which we scrutinised and dissected our narratives in order to unearth our learning sources.

\section{Process and methodology}

To provide some distance from our personal identities and also to allow for a clear engagement with findings from a researcher's perspective, we use pseudonyms (Musa, Sipho, and Langa) to refer to ourselves. Langa and Sipho have known each other for the longest period since, prior to their university appointment, they lived in the same student residence. Langa and Musa had the same supervisor for their doctoral studies and this supervisor organised regular cohort sessions, so they knew each other from these meetings. In 2016, Langa introduced Sipho to Musa and we become collegial friends. In 2017, Langa suggested that we write a paper reflecting on our supervision experiences since we had always shared the challenges we encountered and had sought advice from one another on this facet of our work. We then scheduled several meetings to conceptualise and to work on different components of this paper.

We engaged with our experiences as novice supervisors within the interpretivist paradigm. In line with this worldview, we believe that there is no one ontological single reality; there are, rather, multiple realities because individuals develop subjective meanings of their personal 
experiences and these lead to multiple meanings (Cohen et al. 2011; Creswell, 2012). The interpretivist research worldview formed a framework through which we engaged with our experiences of supervising postgraduate students in our higher education institution. In line with our research positioning, we adopted a qualitative research method given that this approach, in using various ways, aims to understand, describe, and sometimes explain social phenomena from the inside (Flick, 2007).

As Connelly and Clandinin (1990) have asserted, people lead and tell storied lives, so we adopted narrative inquiry because it gave us an opportunity to narrate our stories of lived experiences. This made it possible for us to inquire intimately into our experiences over time and in a university context, which, following Clandinin (2013) and Clandinin and Caine, (2008) was critical to this inquiry. Each of us explored his own experience and the experiences of the other two; this resonated with the sentiments of Clandinin and Caine (2008, p. 543), who maintained that "narrative inquiries begin with inquiring into researchers' own stories of experience." Given that we were both researchers and each other's participants, we followed Clandinin and Connelly (2000, p. 20) who held that "through collaboration between researcher and participants over time, in place, or series of places and in social interaction with milieus" inquiring into and understanding our experience became possible.

For Clandinin (2013), engaging with narrative inquiry necessitates thinking about the three commonplaces of temporality, sociality, and place during the generation and analysis of field texts (known as data in other methodologies). Temporality refers to attending to the past, present, and future of participants (in this case, ourselves). Sociality refers to attending to personal conditions and social conditions concurrently-the personal conditions involve participants' (in this case, our) feelings, hopes, and desires while the social conditions refer to the setting under which participants' (in this case, our) experiences unfold, such as cultural, social, institutional, familial, and linguistic settings. Place refers to the physical boundaries of place or sequence of places in which the inquiry takes place (Clandinin, 2013).

The relationship we had established among ourselves as close colleagues assisted us in executing this inquiry. We were at the same level of experience, we could share our experiences with ease, and we held a reasonable understanding of one another. This enabled us to attend to temporality and sociality in our engagement with each other's experiences. Also, the inquiry took place at our workplace, which is a significant space for all three of us and this worked to our advantage in that we all understood the space.

To generate field texts, we employed an unstructured narrative interview, a pertinent method of doing so in narrative studies, during which a participant is allowed an opportunity to freely relay his or her experiences (Adler \& Clark, 2008; Clandinin, 2013; Olive, 2014). To this end, we set aside two meetings for narrative interviews during which we each took turns being interviewed by the other two. Following the generation of field texts, we each transcribed the interviews. In this way, we ensured that the transcriptions captured accurately what had transpired during the interview sessions. 
In keeping with the narrative inquiry methodology, we analysed the field texts using narrative analysis and the analysis of narrative methods. We exchanged our transcriptions to ensure that each of us did not analyse his own story and, after that, in line with the thinking of Polkinghorne (2002), we engaged in the process of constructing coherent accounts of our experiences. In developing these accounts, we studied transcriptions and discovered plots that connected field text elements. These plots were then used to construct a unified episode hereafter referred to as a re-storied narrative (Polkinghorne, 2002). When we had completed the first level of analysis, we went through the re-storied narratives so that each of us could check that the narratives were a correct representation of our experiences, and also to examine the narratives with the aim of identifying emerging meanings. We then set aside a week to work on the analysis of the narratives. Again, following Polkinghorne (2002), we looked at each re-storied narrative during this week and looked across the three narratives to identify themes that responded to our research puzzle. We present the resultant themes in the findings section where we offer selected excerpts from the re-storied narratives.

The process of engaging with our experiences and our negotiation between the two roles of participant and co-researcher did not compromise the rigor of the inquiry. Instead, the opposite was true. The analysis process in this inquiry followed the verisimilitude principle, which is a criterion for a good literary study and one that aims to make writing seem real and alive. This allows a reader to have a vicarious experience of participants' situations (Creswell, 2008; Loh, 2013) achieved through the twofold member-checking of peer validation and audience validation. These processes are indispensable during the process of reconstructing narratives as Loh (2013) has observed. During the re-storying process, each co-researcher constructed another co-researcher's story. Following this, we three shared all the stories. At this point, the two receiving co-researchers performed dissimilar roles; the story owner engaged in peer validation and the other co-researcher took on the task of audience validation. This process contributed to the truthfulness, as advocated by Loh (2013), of the research presented in this paper.

\section{Findings}

In this section, we discuss four factors that emerged from our re-storied narratives: drawing lessons from research supervisors; learning from senior colleagues; the power of informal dialogues in learning supervision; and reflexivity as a learning avenue.

\section{Drawing lessons from research supervisors}

It was apparent from our narratives that the experience of having been supervised contributed significantly to the development of our supervisor identity. Since we had all been supervised, we found that we all drew from our own supervisors' practices and advice in carrying out the supervision role. According to Kolb (1984), once the experience has been acquired, something has to be done with it. Below, Musa explains how his engagement with his $\mathrm{PhD}$ supervisor translated into a useful resource that influences his supervision. He explained, 
... as I did not know much about supervision and had no confidence [in it] I depended on and drew from my experience of having been supervised as a $\mathrm{PhD}$ student ... I drew from my supervisor's approach to reviewing my work, interacting with me, and also [the work related to] guidance. I then tried my best to provide comparable supervision to my students.

Langa's learning from his supervisor was twofold; he drew from his Master's supervisor's approach to construct his supervisor identity and he also solicited assistance from his current $\mathrm{PhD}$ supervisor, with whom he has established a good relationship. He said,

I had to find my foot in the academic arena, which I did by learning different supervision methods. I drew mostly from my experiences of being a student and my relationships with my former Honours and Master's supervisors. Although my Honours supervisor was a bit distant while my Master's supervisor was supportive, they helped me greatly to construct my own supervisor identity ... I also relied on my $\mathrm{PhD}$ supervisor, to whom I would sometimes send WhatsApp messages or emails enquiring about something or requesting a meeting. In such meetings, we would discuss all my supervision challenges.

In the same vein, Sipho mentioned that his $\mathrm{PhD}$ supervisor performed an advisory role in his learning of supervision. When he encounters challenges, he consults with his supervisor to learn more about supervision. He explained,

I also share my experiences with my $\mathrm{PhD}$ supervisor, who subsequently gives me advice. I remember that she even suggested that I write about my experiences as a young academic and novice supervisor. Through such conversations, I managed to perform this task called supervision and had my students graduate. Additionally, it was during such conversations that the thought of writing this paper was born.

It is clear that the experience of being supervised contributed significantly to our cognition of self, as Hogg et al. (1995) put it in a different context, as novice supervisors. Our relationships with our supervisors constituted a basic supervision experience that formed the basis of our learning and the construction of a supervisor identity. This finding resonates with the sentiments, explained earlier, of Frick and Glosoff (2014) who asserted that novice supervisors draw from their previous supervisors in constructing and carrying out their supervision role. In addition, Lee (2007) has asserted that less capacitated supervisors are likely to emulate the qualities that were demonstrated to them by their supervisors when they were students. Our supervisors also played the role of secondary mentors (see Lee, 2007). Langa and Sipho explained that they solicited supervision assistance from their supervisors when they needed it, and these supervisors provided guidance. So, they may be viewed as secondary mentors because they concentrated on providing support for career development in assisting their mentees with work-based problems and in providing coaching. 


\section{Learning from senior colleagues}

When we examined our re-storied narratives, we noted that a drive to learn came across as another contributor to our development as supervisors. We had an eagerness to learn from our senior colleagues, so we solicited guidance and made ourselves available for workshops that senior academics facilitated in the school. For Musa, co-supervising with senior colleagues and attending the workshops played a significant role in his learning. As we indicated earlier, some institutions require new supervisors to start from the co-supervisor position (Abdullah \& Evans, 2012) and grow from there. He said,

I was invited by two colleagues to co-supervise Master's students with them-one student per colleague. I could not resist this opportunity because I wanted to gain experience and learn more about supervision ... One more thing about support, there are colleagues in the school who offer supervision workshops. They have facilitated two workshops since 2016, and I attended both. I learned a lot from these workshops.

In the same institution but in a different discipline, Langa was allocated a mentor. Although he acknowledges his mentor's work, he did not confine himself to learning only from this mentor. Instead, he identified other excelling academics and drew lessons from them in seeking to diversify his supervision experience. In this way he constantly engages in the cyclical learning process described by Kolb (1968), in that all these experiences with various senior academics are abstracted to develop his learning. He said,

I was not restricted to working with my mentor only; I also consulted and learned from other academics, too. My senior colleagues, whom I perceived to be good at supervision, as evidenced by the many students who graduated under their supervision, became my mentors and role models. I have consulted with most of them over the basics of supervision, particularly on how to support and guide my students in this difficult academic journey.

Sipho also displayed his drive to learn by engaging in many activities with the intention of learning more about supervision. This is what he had to say:

Supervision is not a straightforward activity but a complex encounter. I now understand supervision as an ongoing learning process for both the student and the supervisor. As a supervisor, I had to consult with senior supervisors to gain more confidence and be able to support, guide, and impart knowledge to students.

The senior staff members have always been valuable resources in the development of novice staff members in all sectors; we also took the lead and asserted control for the kind of assistance we required as novice supervisors. We used a bottom-up approach centred around developmental needs in our own learning. As a result, we did not limit ourselves to one veteran staff member or one mentor. Instead, we widened our horizons in the quest to generate a self-conception as supervisors. Lee (2007) has highlighted a need for supervisors, both new and experienced ones, to uncover their conceptions of supervision and examine 
them alongside other supervisors who are doing this. Lee (2007) outlined various paths that supervisors may explore when they want to enhance their skills, including peer learning and support, mentoring, action learning, and attending specialised seminars. As is clear from our narratives, we have done all this with the aim of learning how to fulfil this role to the best of our ability.

\section{The power of informal dialogues in learning supervision}

Informal conversations among colleagues in any workplace are normal and, for us, such conversations formed a significant learning avenue. Although we learn from senior colleagues, as discussed above, we also chat with fellow novice supervisors, and, in this way, we assist one another. These conversations informed some of the self-directed requests for development that we made to senior colleagues. According to Maritz and Prinsloo (2015, p. 974), "the most common way to learn how to supervise is to learn 'on the fly', in other words learning by doing." For Sipho, this is exactly what happened. He explained that

the university considered only the knowledge I had acquired and then gave me the autonomy and trust I did not deserve. I think that a novice academic requires support, be it formal or informal, in order to survive in the position. As for my experience, I felt like I was thrown in the deep end with little idea of what swimming means and was asked to save a person who also did not know how to swim. However, I managed to learn how to swim along the way. My survival was fostered through corridor talks and the informal support of colleagues who had been in the same position.

Likewise, Langa learned from informal corridor talks, conversations over coffee, and during the school, cluster, or discipline events. Apart from this, the power of informal conversations for Langa and his colleagues is evident in their having organised themselves, as novice academics, into a forum that plays a significant role in their academic growth. According to Kolb (1984), new knowledge emerges when existing knowledge is transformed. Langa and his colleagues are engaging in this process collaboratively and, in essence, this enhances the rigor of their discussions. Langa elaborated,

I do learn from corridor talks and from when a colleague pops into my office for coffee or tea and we have discussions on issues relating to teaching, supervision, and research. Apart from this, I am fortunate to be a member of a group of young academics that offers me a brilliant forum in which we meet every week, between Wednesday and Saturday. In our meetings, we work on our PhDs, on other publishing projects, and also have conversations about teaching and supervision. I find this very helpful because we are able to learn from one another.

Musa also pointed out the significance of informal dialogues in his learning how to be a supervisor. He explained that he engages in corridor talks and is also an affiliate in the forum mentioned above. He said, 
There are two further activities from which I generate my understanding of supervision. These include corridor talks and the young academics' forum. With regard to corridor talks, I like to interact with people; it is in my nature. If I am facing a challenge, I usually go to one of my colleagues and enquire informally about the challenge I am experiencing. I ask them how they perform a task I am finding difficult and they advise me ... Regarding the forum, I am a member of the Young Academics' Forum on campus. The forum is constituted of a group of emerging likeminded academics. We discuss many issues relating to our job, and supervision is one of them. If I am experiencing difficulty in my supervision, I check with them, and they give me advice.

Supervision as a role may be viewed as a set of expectations that prescribe behaviour considered appropriate by others (Hogg et al, 1995; McCall \& Simmons, 1978) so, seeking assistance from colleagues formally and informally shows our desire to construct and harness different experiences in order to enact the supervisor role well. Furthermore, critical conversations with colleagues and peers about supervision are significant to the efficacy of both novice and experienced supervisors, as Pearson and Brew (2002) have noted.

\section{Reflexivity as a learning avenue}

Apart from the extrinsic factors such as our research supervisors and colleagues, we also identified intrinsic learning. As novice supervisors, we engaged in a reflexive exercise regarding our supervision experiences, and the exercise enabled us to imagine and re-imagine ourselves. Sipho was fortunate enough to have supervised a physically challenged student; this experience taught him the importance of attending to students' wellbeing, which is significant to the supervision relationship. Khene (2014) has argued that in our supervision relationships, we need to enact a humanising pedagogy, one that is driven by being sensitive to students' backgrounds and learning abilities. Sipho explained,

Among the students I have supervised, there was one older student who had a disability ... I had to find ways to accommodate her because I knew how difficult it was to undertake research and to navigate the challenges she was experiencing. At times, I had to give extra support through giving her extended time to complete a task, and, when necessary, I gave her the chance to submit several drafts. Apart from this, I also gave her my cell phone number so that she could call for support at any time. My human caring factor ensured that this student was not disadvantaged and did not feel neglected in any way by me. I took her struggles and made them mine, and I supported her until I saw her through the academic line.

In similar vein, Musa's supervision experience made him realise that supervision is not only about academic support but also involves social support. As he put it,

In terms of support, I provide both academic and also social support to my students ... Socially, I listen to them and advise on social issues impacting on their studies.

Let me cite one difficult student who always complains about having vast 
responsibilities. When she comes to my office, she will say, 'I am working in a school, and I have a lot of work, including marking. After school, I need to go home, and I have young kids. So, when I arrive at home, I must prepare dinner for them as well as my husband. After finishing the house chores, it is late, and I cannot begin reading due to exhaustion.' In response, I offered her this analogy, and I keep on reminding her of it. I said, 'If you have your kids at home and your brother sends his kids to visit you during the winter holidays, when they arrive, would you chase your kids away? No. You will create space for the visiting kids, and all the kids will have space in your house.' I then told her to look at her MEd studies as her kid and the other tasks like marking, cooking, parents' meetings as visiting kids because these come and go. I told her not to chase her kid (MEd studies) to accommodate the visiting kids. This was one way in which I tried to motivate a student. I speak to students' personal lives so that they feel supported.

While the supervision experience triggered humanity and compassion from Sipho and Musa, Langa's reflexive account was no different. He said,

At first, I struggled with wanting to produce the mini-me because when I started, I wanted to produce students who write, argue, and express ideas like me and have similar knowledge. I expected that students would know what I knew when I was a Master's student, and this was my weakness. I was, however, able to overcome this challenge by reflecting and also consulting with senior colleagues. I came to understand that I should use my knowledge and skills to assist my students in growing in their own right. I recognised that academic growth should be nurtured rather than coerced.

Our learning of supervision and the development of a supervisor identity resulted from various factors, including a rigorous process of learning and re-learning. Engaging in reflexivity was a means through which we accessed knowledge within ourselves. This echoes Kolb (1984), who, from an experiential learning perspective, described learning as involving, recalling, and reflecting on past experiences so that new knowledge could be acquired. This exercise in reflexivity is key to developing role identity, which has been viewed by McCall and Simmons (1978) as an imaginative view of oneself as an occupant of a particular position.

\section{Concluding thoughts}

In concluding this paper, we look back to the research puzzle to which we aimed to respond: What sources of learning are contributing to our supervisor identity development as novice academics in a higher education institution?

From engaging with our experiences as novice supervisors, we identified four sources of learning how to assume the role of supervision: learning from our research supervisors, from senior colleagues, from informal dialogues with colleagues, and by practising reflexivity. We did not undergo a structured comprehensive programme in preparation for the role of 
supervision. Instead, we experienced a unique, cyclical, reflexive, and meaningful learning process. Our narratives show that we played a proactive role in harnessing knowledge pertaining to supervision from different sources. This proactive role afforded us control over our learning and cognition of ourselves as supervisors. As soccer fanatics, we liken our learnings and self-cognition to the setting of a scheme. A coach normally sets the scheme, and it involves the choosing and positioning of players for the field. Likewise, as novice supervisors, we took a coach's position and decided on which players would contribute to our learning.

Our learning as novice supervisors was driven largely by extrinsic factors such as the institution, our colleagues, and the students we supervise. In addition, learning was also driven intrinsically through our reflexivity. These extrinsic and intrinsic factors proved to be equally significant in our learning of the role. In particular, reflexivity was critical in synthesising what we learned from other sources to develop an integrated understanding for ourselves of what it means to be a supervisor. In the quest to best serve research candidates placed under our guidance, we have moved beyond historical learnings (from former supervisors). We exercise agentic dispositions by consciously seeking out potential (re)sources that may enable our further comprehension of how to supervise the knowledge creation process.

It is essential to declare that in this paper we do not attempt to render the institutional supervision training programmes insignificant. Instead, we bring to light unstructured avenues that contributed to our learning of supervision and the development of a supervisor identity. We propose that structured and unstructured approaches to support novice supervisors could coexist in higher education institutions.

\section{Acknowledgements}

We would like to acknowledge, gratefully, the University Staff Doctoral Programme (USDP) for affording us mentorship, capacity building opportunities, and teaching relief to complete our doctoral studies and pursue writing for publication. This programme was administered through the Accelerated Academic Leadership Development Programme (AALDP) at the University of KwaZulu-Natal, in the school of education. We further acknowledge that opinions, findings, and conclusions or recommendations expressed in this paper are those of the authors; the USDP programme accepts no liability in this regard.

\section{References}

Abdullah, M. N. L. Y., \& Evans, T. (2012). The relationships between postgraduate research students' psychological attributes and their supervisors' supervision training. Procedia-Social and Behavioral Sciences, 31, 788-793. 
Abiddin, N. Z., Ismail, A., \& Ismail, A. (2011). Effective supervisory approach in enhancing postgraduate research studies. International Journal of Humanities and Social Science, 1(2), 206-217.

Adler, E. S., \& Clark, R. (2008). How it's done: An invitation to social research (3rd ed.). Thomson Corporation.

Chikte, U. M. E., \& Chabilall, J. A. (2016). Exploration of supervisor and student experiences during master's studies in a Health Science Faculty. South African Journal of Higher Education, 30(1), 57-79.

Clandinin, D. (2013). Engaging in narrative inquiry. Left Coast Press.

Clandinin, D., \& Caine, V. (2008). Narrative inquiry. In L. M. Given (Ed.), The Sage encyclopedia of qualitative research methods (pp. 542-545). SAGE.

Clandinin, D., \& Connelly, F. M. (2000). Narrative inquiry: Experience and story in qualitative research. Jossey-Bass.

Cohen, L., Manion, L., \& Morrison, K. (2011). Research methods in education (7th ed.). Routledge.

Connelly, F. M., \& Clandinin, D. J. (1990). Stories of experience and narrative inquiry. Educational Researcher, 19(5), 2-14.

Creswell, J. (2008). Education research: Planning, conducting, and evaluating quantitative and qualitative research (3rd ed.). Pearson.

Creswell, J. (2012). Educational research: Planning, conducting and evaluating quantitative and qualitative research (4th ed.). Pearson.

Flick, U. (2007). Designing qualitative research. SAGE.

Frick, M. H., \& Glosoff, H. L. (2014). Becoming a supervisor: Qualitative findings on selfefficacy beliefs of doctoral student supervisors-in-training. Professional Counselor, $4(1), 35-48$.

Hogg, M. A., Terry, D. J., \& White, K. M. (1995). A tale of two theories: A critical comparison of identity theory with social identity theory. Social Psychology Quarterly, 58(4): 255-269.

Khene, C. P. (2014). Supporting a humanizing pedagogy in the supervision relationship and process: A reflection in a developing country. International Journal of Doctoral Studies, 9, 73-83. 
Khunou, G., Canham, H., Khoza-Shangase, K., \& Phaswana, E. D. (2019). Black in the academy: Reframing knowledge, the knower, and knowing. In G. Khunou, E. D. Phaswana, K. Khoza-Shangase \& H. Canham (Eds.), Black academic voices: The South African experience (pp. 1-10). HSRC Press.

Kolb, A. Y., \& Kolb, D. A. (2005). Learning styles and learning spaces: Enhancing experiential learning in higher education. Academy of Management Learning \& Education, 4(2), 193-212.

Kolb, D. A. (1984). Experiential learning: Experience as the source of learning and development. Prentice Hall.

Kolb, D. A., Boyatzis, R. E., \& Mainemelis, C. (2001). Experiential learning theory: Previous research and new directions. In R. J. Sternberg \& L.-f. Zhang (Eds.), Perspectives on thinking, learning, and cognitive styles (pp. 227-249). Routledge.

Lee, A. M. (2007). Developing effective supervisors: Concepts of research supervision. South African Journal of Higher Education, 21(4), 680-693.

Lee, A., \& Murray, R. (2015). Supervising writing: Helping postgraduate students develop as researchers. Innovations in Education and Teaching International, 52(5), 558-570.

Leshem, S., Trafford, V. N., \& Bitzer, E. M. (2013). 'Love it when you speak foreign': A trans-national perspective on the professional development of doctoral supervisors in South Africa. South African Journal of Higher Education, 27(4), 781-796.

Loh, J. (2013). Inquiry into issues of trustworthiness and quality in narrative studies: A perspective. The Qualitative Report, 18(33), 1-15.

Maistry, S. M. (2017). Betwixt and between: Liminality and dissonance in developing threshold competences for research supervision in South Africa. South African Journal of Higher Education, 31(1), 119-134.

Manathunga, C., \& Goozée, J. (2007). Challenging the dual assumption of the 'always/already' autonomous student and effective supervisor. Teaching in Higher Education, 12(3), 309-322.

Manathunga, C. (2005). The development of research supervision: "Turning the light on a private space.” International Journal for Academic Development, 10(1), 17-30.

Maritz, J., \& Prinsloo, P. (2015). A Bourdieusian perspective on becoming and being a postgraduate supervisor: The role of capital. Higher Education Research \& Development, 34(5), 972-985.

McCall, G., \& Simmons, J. (1978). Identities and interactions. The Free Press. 
McCallin, A., \& Nayar, S. (2012). Postgraduate research supervision: A critical review of current practice. Teaching in Higher Education, 17(1), 63-74.

National Planning Commission. (2012). National Development Plan 2030. Office of the Presidency. http://www.npconline.co.za

Olive, J. (2014). Reflecting on the tensions between emic and etic perspectives in life history research: Lessons learned. Forum: Qualitative Social Research, 15(02), 1-9.

Pearson, M., \& Brew, A. (2002). Research training and supervision development. Studies in Higher Education, 27(2), 135-150.

Polkinghorne, D. (2002). Narrative configuration in qualitative analysis. In J. Hatch \& R. Wisniewski (Eds.), Life history and narrative (pp. 5-23). The Falmer Press.

Roberts, T. G. (2006). A philosophical examination of experiential learning theory for agricultural educators. Journal of Agricultural Education, 47(1), 17.

Sambrook, S., Stewart, J., \& Roberts, C. (2008). Doctoral supervision . . A view from above, below and the middle! Journal of Further and Higher Education, 32(1), 7184.

Stryker, S. (1968). Identity salience and role performance: The relevance of symbolic interaction theory for family research. Journal of Marriage and the Family, 30(4), $558-564$.

Yousefi, A., Bazrafkan, L., \& Yamani, N. (2015). A qualitative inquiry into the challenges and complexities of research supervision: Viewpoints of postgraduate students and faculty members. Journal of Advances in Medical Education \& Professionalism, 3(3), 91. 